\title{
A Comparative Evaluation of Different Irrigating System for Removal of Modified Triple Antibiotic Pastefrom Root Canal- An In Vitro Study.
}

\author{
*Dr Vishal Changlani, Dr Vaishali Parekh, Dr Parth Desai, \\ Dr NirajKinariwala \& Dr AanchalRana, Dr Pratik Upadhyay. \\ Department of Conservative Dentistry and Endodontics, Karnavati School of Dentistry, Gandhinagar, India. \\ *Corresponding author: ${ }^{*} \mathrm{Dr}$ Vishal Changlani
}

\begin{abstract}
Aim of this study is to compare the efficacy of different irrigation systems for removal of Modified Triple Antibiotic Paste from Root Canal.90 human extracted single rooted teeth were decoronatedand prepared using K files(Mani) up to size 40\# and filled with modified Triple Antibiotic Paste. After preservation for 21 days in the normal saline, roots were divided randomly into 6 groupsPositive control $(n=15), 30$ gauge Side Vented Needle( $n=15)$, EndoVac (Apical negative pressure) ( $n=15)$, EndoActivator (Sonic irrigation system) $(n=15)$, Passive ultrasonic irrigation $(n=15)$ \& Negative control group $(n=15)$. The root halveswere evaluated with stereomicroscope with 40x magnification. The study is stastically analysed by Kruskal-Wallis test.The result showed that EndoVac, EndoActivator groups were effective for apical third,Sidevented needle group was effective for coronal third whereas PUI group was effective for apical third as well as coronal third. Conclusion Passive ultrasonic irrigation system significantly removes the mTAP coronal as well as apical third from the root canal.
\end{abstract}

Key Words: EndoActivator; EndoVac; Modified Triple Antibiotic Paste;Passive ultrasonic; Side Vented Needle;

\section{Introduction}

Regenerative endodontic therapy has been introduced for immaturenecrosed tooth for complete restoration of pulpal function and subsequent completion of root development ${ }^{[1]}$. Endodontic regeneration needs highly bacteria free/steriledenvironment through the use ofintracanal medicament. The most widely used intracanalmedicament in endodontic regeneration is triple antibiotic paste (TAP) described by Hoshino et $\mathrm{al}^{[2]}$ in 1996, which is a mixture of metronidazole, ciprofloxacin, and minocycline. Minocycline has been discarded from TAP because of its discoloration effect ${ }^{[3]}$. Cefaclor has been its replacement and it is described as modified triple antibiotic paste $(\mathrm{mTAP})^{[4]}$. This paste should be removed completely from the root canals to avoid an effect on sealer penetration and tooth discoloration ${ }^{[5]}$, cytotoxic effects to the stem cells.

Conventional syringes are used for irrigation to remove TAP by using Sodium hypochlorite $(\mathrm{NaOCl})$ as an irrigant ${ }^{[5,7]}$ but in case of curved root canals where irrigating solution cannot be reached sufficiently ${ }^{[8]}$ upto apex. So, different devices have been recommended to deliverirrigants, to increase their flow and distribution within the root canal system ${ }^{[9]}$.

The SideVented needle (Canal Clean) 30 gauge, the EndoVac System (Discus Dental, Culver City, CA), the EndoActivator System (EA) (Dentsply, Tulsa, OK), Passive ultrasonic irrigation (PUI) (Acteon Group Ltd, Merignac, France) systems were used.

The Sideventedneedle30 gauge is inserted until resistance was felt and then reducing $1 \mathrm{~mm}$ to prevent obliteration of the root canal lumen ${ }^{[12,13]}$.

The EndoVac is an irrigation system which is works on apical negative pressure, to deliver the irrigantsat the apical third of the root canal and to remove debris via a negative pressure mechanism ${ }^{[10]}$.

The EndoActivator is a sonically activated irrigation system to produce vigorous intracanal fluid agitation that has been shown to increase the efficacy of irrigation compare to conventional syringe irrigation ${ }^{[11]}$.

Passive ultrasonic irrigation activates a small size file or smooth wire in the presence of irrigant solutions and by using principles of acoustic streaming,it disrupts the endodontic biofilm, facilitating better penetration of irrigants throughout the endodontic dentinal walls ${ }^{[9,11]}$.

Inclusion Criteria:-

\section{Materials \& Methodology}

The single rooted teeth with single canal were included.

The root of the teeth werestraight. 


\section{Exclsion Criteria:-}

The curved rootedteeth were excluded.

The single rooted teeth with double canal teeth were excluded.

The teeth were decoronated with diamond disc under water coolant to obtain standardized root length of $12 \mathrm{~mm}$. The root canals were instrumented with Hand $\mathrm{K}$ file (Mani) up to size 40\#. At every instrument change, the root canals were irrigated with $2 \mathrm{ml} \mathrm{3 \%} \mathrm{NaOCl}$ (Eusol) solution. Final irrigation was performed using $5 \mathrm{~mL} 3 \% \mathrm{NaOCl}$ followed by $5 \mathrm{ml}$ of normal saline.

mTAP(modified triple antibiotic paste) was prepared by mixing antibiotic powders compounded in equal proportions of all the tablets Metronidazole (Metrogyl 200mg, J.B. Chemicals), Ciprofloxacin (Ciprodac 250mg, CADILA), and Cefaclor (Distaclor DT 250mg, Menarini) with distilled water. For the antibiotic pastes, a $1000 \mathrm{mg} / \mathrm{ml}$ solution is needed to create a slurry paste which can be used clinically. mTAP was applied to the canal spaces with a lentulospiral till the medicament was visible at the apical foramen. Access to the root canals was temporarily sealed with a cotton pellet and Orafil G (PrevestDenpro Ltd), and the teeth were stored at $37^{\circ} \mathrm{C}$ with $100 \%$ humidity for 21 days.

To simulate clinical conditions, the apices were sealed with temporary cement Orafil G (PrevestDenpro Ltd). The specimens were randomly divided into 6 groups: 2 groups for positive control \& negative control, 4 groups were according to the irrigation regimens used. In 15 teeth, mTAP was not removed (positive controls), and another 15 teeth were not filled with mTAP (negative controls).

\section{Group 1: Positive Control}

The samples of this group were kept entirely filled with mTAP.

\section{Group 2: SideVented Needle}

A 30-Gauge side vented (Canal clean) irrigation needle was inserted until resistance was felt and then reducing $1 \mathrm{~mm}$ to prevent obliteration of the root canal lumen and irrigation was performed with $10 \mathrm{~mL} 3 \% \mathrm{NaOCl}$ solution for 1 minute.

\section{Group 3: EndoVac}

The canals were first irrigated for 30 seconds with $5 \mathrm{~mL} 3 \% \mathrm{NaOCl}$ using macrocannulas for $2 / 3^{\text {rd }}$ of the working length. The microcannulas were then inserted to the full working length, and the canals were irrigated with $5 \mathrm{~mL} 3 \% \mathrm{NaOCl}$ for 30 seconds.

\section{Group 4: EndoActivator}

Ten milliliters of $3 \% \mathrm{NaOCl}$ was flushed into the canal using a 261/2 gauge syringe and activated using an EA handpiece set at the highestspeed with a red (25/04) tip inserted $2 \mathrm{~mm}$ short of the working length for 1 minute.

\section{Group 5: PUI}

Ten milliliters of $3 \% \mathrm{NaOCl}$ was agitated using a size $15 \mathrm{~K}$-file coupled to the file-holding adapter of a (SatelecActeon Group Ltd). The ultrasonic file was placed into the canal $1 \mathrm{~mm}$ short of the working length without touching the walls, enabling it to vibrate freely. The ultrasonic file was activated at power setting 6 for 1 minute, and the irrigants were continuously delivered at a rate of $10 \mathrm{ml} / \mathrm{min}$ through the unit.

\section{Group 6: Negative Control}

The samples of this group were kept entirely unfilled with mTAP.

In the last $2 \mathrm{ml}$ distilled water was used to remove any remaining $\mathrm{NaOCl}$. The canals were dried with paper points, and longitudinal grooves were prepared on the buccal and lingual surfaces of each root with a diamond disk without perforating the canal, canal was sectioned using chisel and mallet. 15 roots in each group were sectioned into 2 halves; thus, 30 samples were obtained from each group $(n=30)$. The amount of remaining medicament at each root half was evaluated. Images of the coronal (12 $\mathrm{mm}$ from apex), middle ( 8 $\mathrm{mm}$ from apex), and apical (4 $\mathrm{mm}$ from apex) thirds of the root half surfaces were evaluated for this purpose using a digital camera mounted on a stereomicroscope (Labomed, csm2) at 40x magnification and transferred to the computer. The amount of mTAP remaining in the canal was scored using the following scoring system described by Van Der Sluis et al ${ }^{(\mathbf{1 4})}$ score 0 means the canal was empty; score 1 meansmTAP was present in less than half of the canal; score 2 meansmTAP covered more than half of the canal; and score 3 means the canal was completely filled with mTAP.

Statistical analysis were performed with the Kruskal-Wallis. The level of statistical significance was set at $95 \%$ confidence $(\mathrm{P}<0.05)$. 


\section{Results}

The positive control group showed that the canal walls were completely filled with mTAP, and the negative control group showed no mTAP on the canal walls.

None of the experimental groups showed complete removal of mTAP from the root canals. The Kruskal-Wallis test revealed that there were statistically significant differences among the experimental groups $(\mathrm{P}<0.05)$.

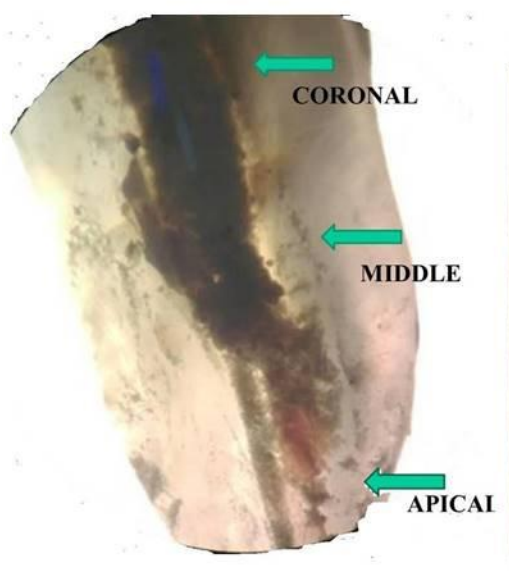

Figure 1

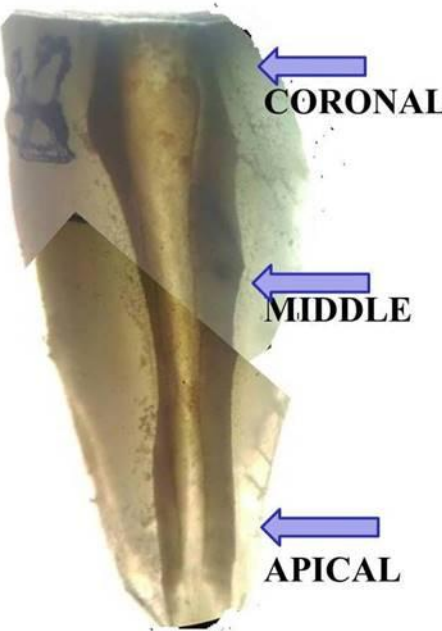

Figure 4

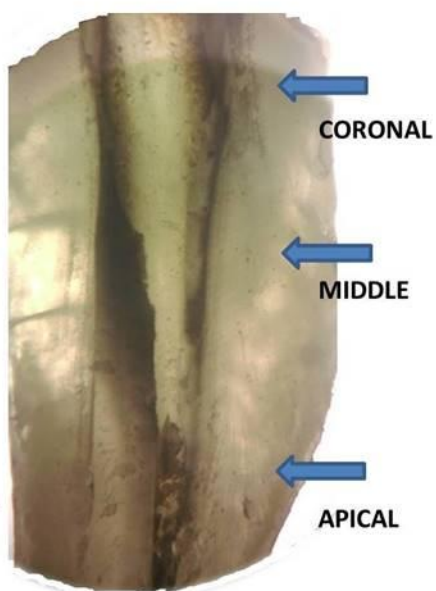

Figure 2

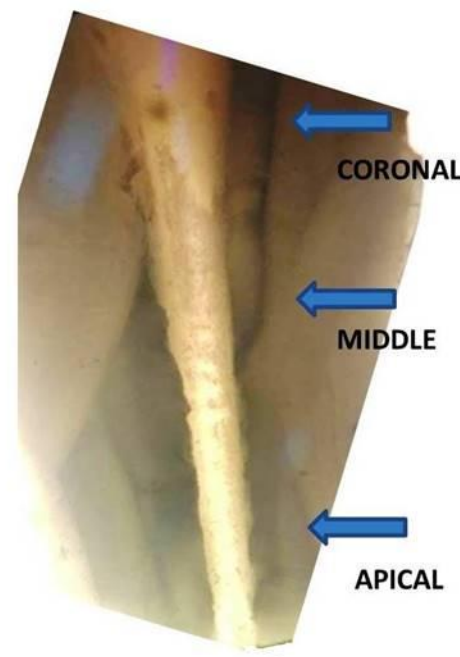

Figure 5

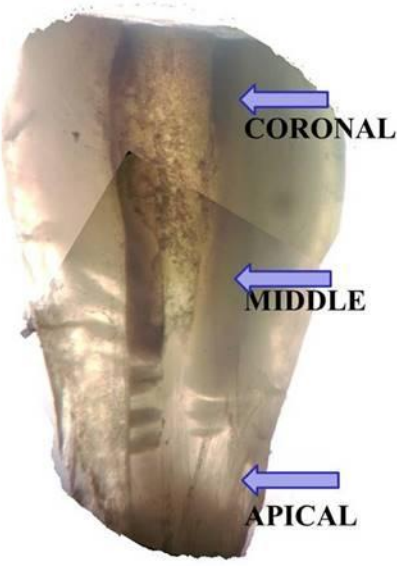

Figure 3

Figure 1- Stereomicroscope image of root half of Positive control group.

Figure 2- Stereomicroscope image of root half of Sidevented Needle group.

Figure 3- Stereomicroscope image of root half of Endovac group.

Figure 4- Stereomicroscope image of root half of Endoactivator group.

Figure 5- Stereomicroscope image of root half of PUI group.

Figure 6- Stereomicroscope image of root half of Negative control group.

Table 1- Mean value of modified triple antibiotic paste for Apical third area..

\begin{tabular}{|l|l|}
\hline GROUPS & MEAN VALUE \\
\hline Positive control & $\mathbf{8 3 . 0 0}$ \\
Side Vented Needle & $\mathbf{6 3 . 5 3}$ \\
& \\
Endo Vac & $\mathbf{3 5 . 4 7}$ \\
Endo Activator & $\mathbf{3 2 . 5 0}$ \\
& \\
Passive Ultra Sonic Negative & \\
control & \\
& $\mathbf{3 2 . 5 0}$ \\
& $\mathbf{2 6 . 0 0}$ \\
\hline
\end{tabular}


Table 2- Mean value of modified triple antibiotic paste for Middle third area.

\begin{tabular}{|l|l|}
\hline GROUPS & MEAN VALUE \\
\hline Positive control & $\mathbf{8 2 . 0 0}$ \\
Side Vented Needle & $\mathbf{2 6 . 6 0}$ \\
Endo Vac & $\mathbf{4 3 . 5 0}$ \\
Endo Activator & $\mathbf{6 4 . 1 0}$ \\
Passive Ultra Sonic Negative & $\mathbf{4 7 . 8 0}$ \\
control & $\mathbf{1 9 . 0 0}$ \\
\hline
\end{tabular}

Table 3- Mean value of modified triple antibiotic paste for Coronal third area.

\begin{tabular}{|l|l|}
\hline GROUPS & MEAN VALUE \\
\hline Positive control & $\mathbf{7 9 . 5 0}$ \\
Side Vented Needle & $\mathbf{3 4 . 8 3}$ \\
Endo Vac & $\mathbf{5 9 . 8 3}$ \\
Endo Activator & $\mathbf{6 1 . 0 0}$ \\
Passive Ultra Sonic Negative & $\mathbf{2 2 . 8 3}$ \\
control & $\mathbf{1 5 . 0 0}$ \\
\hline
\end{tabular}

Table 1 showed that at the apical third, Side vented needle group was less efficient for removing the pastewhereas no statistically significant difference $(\mathrm{P}>.05)$ was found among the Endovac, Endoactivator and PUI irrigation activation regimens.

Table 2 showed at the middle thirds, Side vented needle group was more efficient for removing the paste, on the other side Endoactivator was less efficient for removing the paste. There was no stastical significant difference $(\mathrm{P}>.05)$ between PUI group and Endovac group.

Table 3 showed at the coronal thirds, PUI group and Side vented needle group were efficient for removing the paste, on the other side there were no stastical significant difference $(\mathrm{P}>.05)$ between Endovac group and Endoactivator group.

\section{Discussion}

There are many medicaments which can be used for regeneration purposes such as Calcium hydroxide, Triple antibiotic paste but due to certain drawbacks such asbacterial resistance \& discoloration of tooth, these are avoided. Kim et $\mathrm{al}^{[5]}$ reported that minocycline from TAP was the cause of discolorations. It has also been proposed that the use of cefaclor instead of minocycline in TAP diminishes the discoloration effect ${ }^{[4]}$. In present study cefaclor is used. In case of regeneration ${ }^{[1]}$ mTAP is placed within the canal for 21 days, and in this study mTAP is placed for 21 days within the root canal.

This study has an aim for comparing the efficacy of the different irrigation systems in the removal of mTAP from the entire root canal wall. Anin vitro,closed-ended canal model was used to simulate theclinicalconditions ${ }^{[15]}$. Various methods have been used to check the amount of residues on the canal walls, such as the use of digital photographs, stereomicroscopes, scanning electron microscopes, micro-computed tomographic imaging, and spiral computed tomographic imaging ${ }^{[16-19]}$. In the presentstudy stereomicroscope was used at 40x magnification because of easy availability and accuracy of result\&echonomical factor.

The agitation of the irrigantis required to remove intracanalmedicaments from root canal walls effectively as well as canalirregularities when compared with using the endodontic syringeirrigation alone. At the same time, it is quite difficult foradequate deliveryof the irrigant to the working length with syringe irrigation. So, In the present study different irrigation systems are used and compare their efficacy to remove the antibiotic paste.

According to result of this study,PUI is more effective than SideVented needle, EV and EA for coronal third as well as apical third to removemTAP from the root canals. PUI is based on the transmission of energy from an ultrasonically oscillating instrument to the irrigating solution inside the root canal ${ }^{[\mathbf{1 4}]}$. The high shear stress is generated due to acoustic microstreaming \& cavitation within the irrigant flow by PUI (Acteon Group Ltd, Merignac, France) may explain its efficiency in removing intracanal medicament from the root canals ${ }^{[20]}$.

Results of the study showsSideVented(Canal Clean) 30 gauge needlecan efficiently remove the mTAP from middle third followed by coronal third due to high velocity of irrigant flow is generated from the canal wall near to the needle outlet towards coronally.

Results of the study showsEV and EA were significantly efficient for the removal of mTAP at the apical third when compared with the middle and coronal thirds ${ }^{[10]}$. In endodontics, the EV system has been introduced to solve the problem of vapour lock and lack of apical irrigation at the root end because it works by applying apical negative pressure at full working length ${ }^{[10]}$. According toSchoeffel et al., the EV system showed the lowest scores at the apical third when compared with the middle and coronal thirds. EndoActivator (Dentsply, Tulsa, OK) ${ }^{[11]}$ is an irrigation system which activates irrigant solution sonically to produce vigorous intracanal fluid agitation that has been shown to increase the efficacy of irrigation. 


\section{Conclusion}

The study is concluded that none of the irrigation system can completely remove mTAP from the root canals. When taking esthetic considerations into account, it is important to remove mTAPfrom coronal third, thathas potential for discoloration to the root dentin, especially in the coronal third. In this study, PUI can effectively removethe mTAP in the coronal as well as apical part of the root canals. The combination of irrigation activation regimens might be highly effective to remove mTAP from entire canal.

\section{References}

[1]. Diogenes A, Henry MA, Teixeria FB, Hargreaves KM. An update on clinical regenerative endodontics.Endod Topics 2013;28:2-23.

[2]. Hoshino E, Kurihara-Ando N, Sato I, et al.In-vitro antibacterial susceptibility of bacteria taken from infected root dentine to a mixture of ciprofloxacin, metronidazole and minocycline. IntEndod J 1996;29:125-30.

[3]. Trope M. Treatment of the immature tooth with a non-vital pulp and apical periodontitis. Dent Clin North Am 2010;54:313-24

[4]. Thibodeau B, Trope M. Pulp revascularization of a necrotic infected immature permanent tooth: case report and review of the literature. Pediatr Dent 2007;29:47-50.

[5]. Kim JH, Kim Y, Shin SJ, et al. Tooth discoloration of immature permanent incisor associated with triple antibiotic therapy: a case report. J Endod 2010;36:1086-91.

[6]. Tawfik H, Abu-Seida AM, Hashem AA, Nagy MM. Regenerative potential following revascularization of immature permanent teeth with necrotic pulps. IntEndod J 2013;46:910-22

[7]. Zhu W, Zhu X, Huang GT, et al. Regeneration of dental pulp tissue in immature teethwith apical periodontitis using platelet rich plasma and dental pulp cells. IntEndod J 2013;46:962-70.

[8]. Villa MH, Bernardineli N, Cavenago BC, et al. Micro-computed tomography study of the internal anatomy of mesial root canals of mandibular molars. J Endod 2011;37:1682-6.

[9]. Gu LS, Kim JR, Ling J, et al. Review of contemporary irrigant agitation techniques and devices. J Endod2009;35:791-804.

[10]. Schoeffel GJ. The EndoVac method of endodontic irrigation, part 2-efficacy. DentToday 2008;27:82-4. 86-7.

[11]. Ahmad M, Pitt Ford TJ, Crum LA. Ultrasonic debridement of root canals: acoustic streaming and its possible role. $J$ Endod 1987;13:490-9.

[12]. Boutsioukis C, Lambrianidis T, Kastrinakis E. Irrigant flow within a prepared root canal using various flow rates: A computational fluid dynamics study. IntEndod J. 2009;42:144-55.

[13]. Chow TW. Mechanical effectiveness of root canal irrigation. J Endod. 1983;9:475-9.

[14]. Van der Sluis LW, Wu MK, Wesselink PR. The evaluation of removal of calcium hydroxide paste from an artificial standardized groove in the apical root canal using different irrigation methodologies.IntEndod $J$ 2007;40:52-7.

[15]. Tay FR, Gu LS, Schoeffel GJ, et al. Effect of vapor lock on root canal debridement by using a side-vented needle for positivepressure irrigant delivery. J Endod 2010;36: 745-50.

[16]. Arslan H, Capar ID, Saygili G, et al. Efficacy of various irrigation protocols on the removal of triple antibiotic paste. IntEndod $J$ 2014;47:594-9.

[17]. Karabucak B. Comparison of final irrigation techniques in removal of calcium hydroxide. AustEndod J 2013;39:116-21.

[18]. Wiseman A, Cox TC, Paranjpe A, et al. Efficacy of sonic and ultrasonic activation for removal of calcium hydroxide from mesial canals of mandibular molars: a microtomographic study. J Endod2011;37:235-8.

[19]. Nandini S, Velmurugan N, Kandaswamy D. Removal efficiency of calcium hydroxide intracanal medicament with two calcium chelators: volumetric analysis using spiral CT, aninvitrostudy. J Endod 2006;32:1097-101.

[20]. Jiang LM, Verhaagen B, Versluis M, van der Sluis LW. Influence of the oscillation direction of an ultrasonic file on the cleaning efficacy of passive ultrasonic irrigation. J Endod 2010;36:1372-6

[21]. Lenherr P, Allgayer N, Weiger R, et al. Tooth discoloration induced by endodontic materials: a laboratory study. IntEndod $J$ 2012;45:942-9.

Dr Vishal Changlani. "A Comparative Evaluation of Different Irrigating System for Removal of Modified Triple Antibiotic Pastefrom Root Canal- An In Vitro Study." Jdms 16.7 (n.d.): 12-16. 